\title{
A Web-based Application for Residential and Non-Residential Centers and Institutions of DSWD (Department of Social Welfare and Development) Region III Records Management and Incident Reporting
}

\author{
Rene D. Laguna
}

\begin{abstract}
The study aims to develop a web-based application for Residential and Non-Residential Centers and Institutions of DSWD Region III to manage their records and automate the reporting of incidents. Moreover, it also enables citizens to report incidents concerning drug dependents, abandoned or neglected and abused individuals to appropriate centers or institutions. The application has three user access level for efficient and secure managing and sending different types of reports. In the initial data collected, the results show that centers and institutions have many different reports that are being generated. Organizing these reports and searching through them is always a challenge. Concerned citizens reports the incidents they have encountered but experience problems in doing it such as to whom it should be reported and the way it should be reported. Evaluation was done by end users in terms of its functional requirements and by the IT experts in terms of the technical aspect in particularly about performance and security. Based from the evaluation, the webbased application has provided the functionalities needed in managing the records of different centers and institutions and regional office. This could help them in handling these records efficiently. Moreover, incidents reported by concerned citizens has been sent to appropriate centers and institutions thereby helping to ease the incident reporting process. As for the recommendation, web-based application would be more usable as mobile web application. Reports generated should be more dynamic. Add more features to maintain the security and confidentiality of the information of reported incidents.

Index Terms-Centers and Institutions, Incident Reporting, Records Management, Web-based Application
\end{abstract}

\section{INTRODUCTION}

Whatever type of government is implemented in a particular country, the officials in the government has the responsibility of protecting their citizens from possible harm and threats whether internally or externally and, providing goods and services for the improvement of their social welfare. These duties are always be observed and maintained most of the time by the government to ensure safety and security to its citizens.

The social welfare state of every citizen can be highly influenced and affected by the government. Government can cushion the inability of citizens to provide for themselves, particularly in the vulnerable conditions of youth, old age, sickness, disability and unemployment due to economic forces beyond their control. At its best, however, it is providing an infrastructure of care to enable citizens to flourish socially and economically in the same way that an infrastructure of competition does. It provides a social security that enables citizens to create their own economic security [1].

The government established the means of delivering the services to its citizens through the provision of public service agencies primarily focusing on health care, sanitation, livelihood, education, and criminal justice People care about these public services and depend on them being delivered well. Public services provide the most common interface between people and the state, and their functioning shapes people's sense of trust in and expectations of government. At a national level, public services underpin human welfare and economic growth [2].

Delivering services to citizens of the government is the center of the efforts implemented by different agencies. At present, citizens presume more transparent, accessible and responsive services from the public sector; and demands to these conditions are rising. Efforts have already been made by various governments through the delivery of innovative technologies with the use of online portals or "one-stop shops" but still realized that meeting public expectations were still not achieved. Citizens tell public-sector officials that they continue to feel frustrated by cumbersome or confusing websites and find it's often still necessary to speak with multiple parties before their question is answered or their request is completed. As a result, governments face not only declining citizen satisfaction and eroding public trust but also increasing costs associated with delivering services across multiple channels [3].

Like any other countries, Philippines has developed its own infrastructure through the establishment of different government or cabinet agencies in delivering these services to intended citizens. These government services come in may form. They could be in terms of education, employment, health, housing, social services and many others. One particular cabinet member that handles social services and assign in supervising and supporting the social welfare of the community is the Department of Social Welfare and Development (DSWD). The DSWD Formulate policies and plans to provide direction for the development 


\section{A WEB-BASED APPLICATION FOR RESIDENTIAL AND NON-RESIDENTIAL CENTERS AND INSTITUTIONS OF DSWD (DEPARTMENT OF SOCIAL WELFARE AND DEVELOPMENT) REGION III RECORDS MANAGEMENT AND INCIDENT REPORTING} Develops and enriches existing programs and services especially for the children and youth, women, family and communities, solo parents, older persons and persons with disabilities (PWDs). It also registers, licenses and accredits individuals and groups involved in social welfare and development services; sets standards and monitors individuals and groups if they comply with these standards [4].

Among the programs or services managed by DSWD, this study will focus on the Residential and Non-Residential Facilities. As stated in the DSWD website, the program aims to provide residential care services to disadvantaged and vulnerable sectors. Moreover, training and rehabilitation to persons with disabilities through the establishment of its centers and residential care facilities. There are a total of 915 private social welfare centers and institutions established at present and they are all licensed by the DSWD. Funds being in these centers and institutions are generated mostly from international funding agencies and the private sector. These institutions are not subsidized by the government [5]. The DSWD has provided a public information about how the to report incident about abused individuals. The victims themselves may file the complaint, or on their behalf, it could be their parent or legal guardian, relatives, barangay chairman, social workers, or at least (3) concerned citizens. Furthermore, any person who reported a child abuse case shall be assured of confidentiality and anonymity, and free from any civil and administrative liability.

The means to report these incidents are done through calling the hotline numbers available in the website of DSWD and other government agencies related to these incidents such as Commission on Human Rights (CHR), National Bureau of Investigation (NBI), Philippine National Police (PNP), Department of Justice and others [6].

Integrating technologies in these services can significant change as time passes. As population increases, public sector organizations will continue to find it increasingly difficult to satisfy the needs of their citizens. One of the key drivers for delivering improvements in service delivery in the public sector is technology, which is fundamentally changing the of life, work and interact with each other. Shifts to digital technologies mean that citizen expectations for technology-enabled government services have risen significantly in recent years. This shift in expectations, coupled with the financial pressure on government to transform and do more with less, presents new opportunities to deliver better outcomes for citizens, businesses and public servants themselves [7].

Philippines is a great venue for ICT development and adoption. According to Faith Campo, a digital media enthusiast, as Philippine companies rely on digital platforms to connect with their markets, the amount of consumer information they gather also increases. The generated big data can help them devise smarter, revenue-generating strategies. So, there's a need to invest on tools that can help make sense of these large heaps of information. Examples are data analytics software, automation tools, workforce optimization solutions, and others. By 2020, it's predicted and delivery of social welfare and development services.

that revenues produced by these tools will be twice that of revenues generated by non-tech-based sources [8].

Currently, the DSWD Regional 3 and its centers and institutions have not used any innovative ICT tool or application in handling the incidents reported to them. According to Ms. Divina Silos, head of the center named Haven which is located in Magalang, Pampanga, the usual process is they will be called by the one who witness the incident, DSWD service worker or authorities of government organization affiliated to them through a telephone or mobile phone and report incident. The received phone call is not sufficient for them so they have to a personally, particularly the DSWD service worker, to know all the details of the report.

Every report that is received by the DSWD is recorded to the saved spreadsheet and word document files of centers and institutions. These reports created will then be send to the DSWD Regional Office. Depending on the report generated, reports are sent weekly, monthly and quarterly. The centers and institutions produce a printed copy of these files and keep them in a filing cabinet.

With all of these details provided regarding ICT, the researcher has come up with the proposal of integrating ICT on how DSWD manages the record keeping of the different institutions and centers they are supervising. Moreover, the proposal will also include the reporting of neglected children or abused individuals wherein these reports will be directly sent to the respective institutions and centers of DSWD. This ICT innovation will be in the form of a Webbased Application. Technically, the information system to be created would be accessible through any device that are actively connected to the Internet.

This study aims to developed a web-based application to handle the records management and incident reporting that are occurring in the DSWD Region III. As soon as the application is accomplished, it would be evaluated by IT experts, center heads and government citizens.

\section{RELATED LITERATURE AND STUDIES}

According to $\mathrm{Fe}$ Angela M. Verzozain in her article entitled, "Promoting Records Management in Government, the average of worker spends $30 \%$ of the time searching for or recreating lost documents. The average organization makes 19 copies of each document. Moreover, she stated that with good record management it can ensure statutory and regulatory compliance, preserve the rights of citizens, support better decision making, safeguard vital information preserve organizational memory, reduce operating costs and minimize litigation risks [9].

Good records management plays vital role in the operations in the government. According to Judith Lamont Ph.D., records management is generating an unusual degree of passion lately. Long held captive to an image of dusty file cabinets in the basement, accessed only when needed for legal purposes, records management is now being recognized as a critical component in information governance, a vital process that extends beyond-but 
includes - records management. The sheer volume of information with which organizations must cope is an important aspect of records management, because proper application of policies will eliminate unnecessary documents [10].

Use of IT in the government surely enhance the accomplishment of tasks and make operations more efficient. According to the study entitled, Information Technology for Good Governance, IT promotes good governance in three basic ways: (1) by increasing transparency, information, and accountability; (2) by facilitating accurate decision-making and public participation; and (3) by enhancing the efficient delivery of public goods and services. The citizen's right to gain access to public documents is supported under the country's constitutional framework. Promotion of this right is pursued through the government's computerization program and the availability of these documents through the Internet. Many government agencies use IT facilities to tell the public about their accomplishments, achievements, programs, and plans. The availability of information helps people, especially those who live in the provinces, to access the data that they need without going to the nation's capital. Information about government operations is a basic requirement in fostering transparency in governance. The use of IT could enable the government, as well as civil society, to inform the people of their rights and privileges [11].

Using web-based applications in incident reporting could enable an organization to handle these reports better. According to the study conducted by Jonathan Hazan, incident reporting has long been established as a key component of patient safety in almost all healthcare and related settings. The analysis of incidents to determine why they happen and put in place corrective actions enables us to learn from things that go wrong and protect patients from harm in the future. The introduction of electronic incident reporting using web forms to replace paper has improved efficiency and increased the number of reports collected. There still remain significant barriers to learning from incidents, however. These include issues to do with the design of the systems as well as issues concerning organizational culture [12].

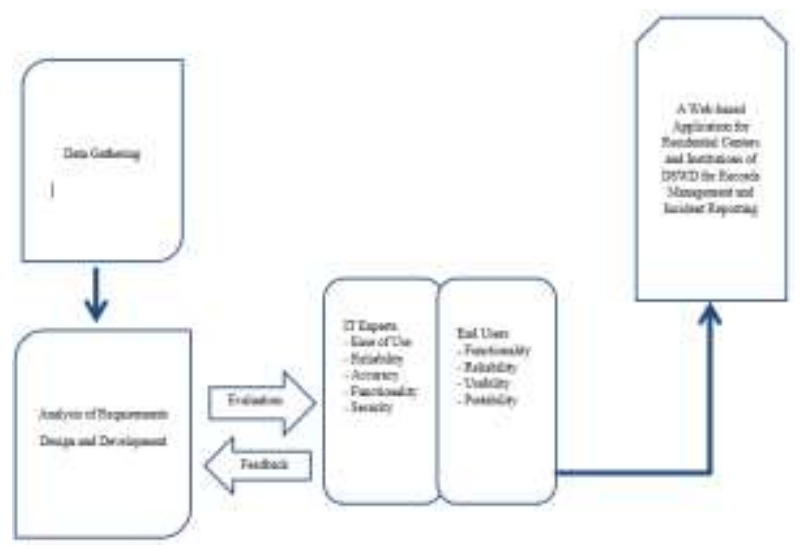

Fig 1. Conceptual Paradigm

\section{METHODS OF STUDY AND SOURCES OF DATA}

The study used Research and Development (R\&D) Approach wherein a web-based system that will be developed will be designed, created, tested and evaluated in terms of its functional and non-functional requirements. This research design was chosen by the researcher to justify the need to design and developed a web-based system that will provide improvement or solutions to the difficulties or problems being experience or will be experience by the DSWD managing records of the different centers and institutions under their management.

This study is divided into three different phases which include analysis and design, development, and evaluation of a Web-based Application for Residential Centers and Institutions of DSWD for Records Management and Incident Reporting.

In the analysis phase, careful observation and investigation are conducted by the researcher to identify the areas of improvement wherein innovation through IT can be applied or implemented. Data collection plays a vital role in formulating the right business requirements which will use as a basis on how the users can easily migrate to the web application. This business requirements were translated to user requirements that will consider by the researcher in developing the web application. In the development phase, the web-based application that will be developed will use Rapid Application Development (RAD) Methodology. This development model utilizes both rapid cycles of iterative development and prototyping. The researcher uses this approach to emphasize more on the development of the prototype and make sure all the necessary functionalities are available. In the evaluation phase, the researcher provided the prototype, design and user interface of the web application to the end users and IT experts. Testing and dry - runs would be performed to evaluate the performance and usefulness of the web application. In terms on the technical aspects or non-functional requirements of the web application, the IT experts will be the one validating these functionalities. While the end users will be the one evaluating the functional requirements. To document this evaluation process, both groups will be provided with survey questionnaires to gather necessary information which late can be used in improving the functionalities of the web application.

The instruments use for collecting relevant data from the target participants include survey questionnaires consisting of pre and post survey, and interview guide questions. Post survey questions were based from the ISO/IEC 25010 to have a valid justification on the quality of the web-based application. The figure below illustrates the

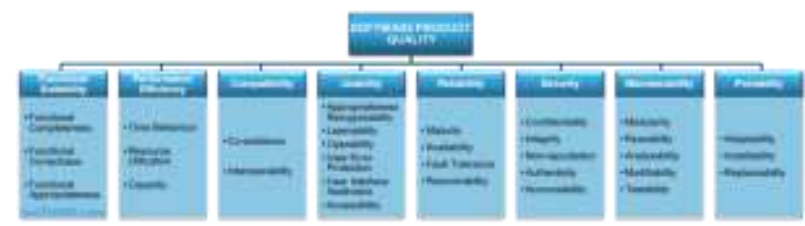

Fig 2. ISO/IEC 25010 Model

Source: ISO/IEC 25010, Retrieved April 10, 2019 from https://iso25000.com/index.php/en/iso-25000standards/iso-25010

Published By: 


\section{A WEB-BASED APPLICATION FOR RESIDENTIAL AND NON-RESIDENTIAL CENTERS AND INSTITUTIONS OF DSWD (DEPARTMENT OF SOCIAL WELFARE AND DEVELOPMENT) REGION III RECORDS MANAGEMENT AND INCIDENT REPORTING}

The researcher targeted at least 200 number of participants for answering the pre-survey questionnaire. But due to the time constraints, there were only 132 participants who were able to provide answers on the pre-survey questionnaire. Purposive sampling was used to select these participants. The criteria for selecting these participants is that if they are aware about the primary roles and responsibilities of the DSWD. In the post survey, same parameters were used. However, there are only 104 that answer the post survey out of the targeted 200. The following formula below would be used in getting the mean and interpreting the post survey results:

Weighted Arithmetic Mean Formula:

$\mathrm{X}=(\mathrm{x} 1 \mathrm{f} 1+\mathrm{x} 2 \mathrm{f} 2+\ldots+\mathrm{xnfn}) /$ number of respondents where:

$\mathrm{xi}=$ the number of different values of $\mathrm{x}$ in the given set

$\mathrm{fi}=$ frequency

Interviews were conducted with two center heads and one regional director. Questions were about the process and operations in DSWD Region III concerning their centers and institutions. The table below shows the criteria on how the web application will be evaluated by target participants.

Table I. Range of Values for Software Quality Evaluation

\begin{tabular}{|c|c|c|}
\hline Scale/Ranges & Index & $\begin{array}{c}\text { Verbal } \\
\text { Description }\end{array}$ \\
\hline $4.51-5$ & 5 & Excellent \\
\hline $3.51-4.5$ & 4 & Very Good \\
\hline $2.51-3.5$ & 3 & Good \\
\hline $1.51-2.5$ & 2 & Fair \\
\hline $1-1.5$ & 1 & Poor \\
\hline
\end{tabular}

\section{RESULTS}

In the interview conducted with the center heads of DSWD Region III, their record management revolved around word documents and spreadsheets stored in computer hard drives and printed and stored in filing cabinets. There are reports that they need to provide to the regional office every month. Most of the time these reports are too much to handle for them. Certain challenges such as searching through archived documents and organizing them the reports relating to abused, neglected or abandoned individuals, there is a need for them to communicate them to the regional office every now and then. In terms of reporting the incidents, the social worker the always the one who file reports. This may be done by going to the centers done thru personal visit to the location of the incident and talking to the involved individuals before the report will be entertained. There are times that they also get details of abused incidents from court orders, police reports and regional office since reporting can also be done to those organizations.

With the pre-survey conducted which were participated by 132 individuals, the results show that there were $37 \%$ of them who encountered abused, neglected or abandoned incidents and most of them do not know to whom and how it should be reported. The remaining $63 \%$ did not encounter
$\mathrm{X}=$ the mean in a storage is entirely putting them into a dilemma. With personally or thru a phone call. Verification of the report is

such incidents but were asked there is a chance they would witness, most them also said that they did not know to whom or how it should be reported.

Table II. Person who had encountered incidents relating to abused, neglected or abandoned individuals

\begin{tabular}{|c|c|c|}
\hline Response & Frequency & Percentage \\
\hline YES & 48 & $37 \%$ \\
\hline NO & 84 & $63 \%$ \\
\hline & & \\
\hline Total & 132 & $100 \%$ \\
\hline
\end{tabular}

Table III. Person who encountered abovementioned incidents and knows the reporting process

\begin{tabular}{|c|c|c|}
\hline Response & Frequency & Percentage \\
\hline YES & 15 & $31 \%$ \\
\hline NO & 33 & $69 \%$ \\
\hline & & \\
\hline Total & 48 & $100 \%$ \\
\hline
\end{tabular}

Table IV. Person who did not encounter the abovementioned incidents and knows the reporting process

\begin{tabular}{|c|c|c|}
\hline Response & Frequency & Percentage \\
\hline YES & 19 & $23 \%$ \\
\hline NO & 65 & $77 \%$ \\
\hline & & \\
\hline Total & 84 & $100 \%$ \\
\hline
\end{tabular}

In the post survey conducted with the end users consisting of the regional office director, center heads and concerned citizens, the results show that the software quality of the developed has achieved an overall weighted mean of $\mathbf{3 . 9 1}$ which means that it is Very Good in terms of adapting to the operations and processes of the DSWD regional office in terms of record management of centers and institutions, the centers and institutions in terms records management of the reported incidents and the concerned citizens in reporting of incidents relating to abused, neglected, or abandoned individuals. The 3.91 computed value has been computed by getting the grand mean of all the average mean of each criteria.

Table V. Web-based Application Evaluation Result

\begin{tabular}{|c|c|c|}
\hline Criteria & Weighted Mean & $\begin{array}{c}\text { Verbal } \\
\text { Interpretation }\end{array}$ \\
\hline $\begin{array}{c}\text { Functional } \\
\text { Suitability }\end{array}$ & 3.89 & Very Good \\
\hline $\begin{array}{c}\text { Performance } \\
\text { Efficiency }\end{array}$ & 3.75 & Very Good \\
\hline Compatibility & 4.37 & Very Good \\
\hline Usability & 4.46 & Very Good \\
\hline Reliability & 4.27 & Very Good \\
\hline Security & 3.25 & Good \\
\hline Maintainability & 3.25 & Good \\
\hline Portability & 4.00 & Very Good \\
\hline
\end{tabular}

Published By: 


\section{CONCLUSION}

Based from the results of the interview from the center heads, the DSWD needs to improve the process of their record management in terms of incidents that are being reported and the reports that needed to be sent to the regional office.

Based from the results of the pre-survey which is mostly focus in reporting of incidents by concerned citizens, there is also a need to change the way on how these incidents are being reported to the centers and handled since there are problems encountered by those who and want to report. These problems include the procedure on how to report incidents, what details needed and who it should be reported. Resolving these issues can help the DSWD Region III address reported cases efficiently.

With these data collected, the researcher had developed a web-based application that intends to address the necessary improvement in terms of record management and reporting of abused, neglected and abandoned individuals.

The developed web-based application has been evaluated by concerned citizens, center heads, regional director and IT experts. Based from their evaluation, the web-based application has able to provide all the necessary functionalities needed to perform the operations of DSWD Region III regarding records management of concerning centers and institutions. Also, the centers and institutions were also able to handle the records of reported incidents sent to them. Lastly, the concerned citizens would not need to worry about the overall process of reporting since the web-based application would be one who will perform the sending of reports to the respective centers and institutions.

However, as for recommendation based from the results of the evaluation, the web-based application has to be more secure since it would handle sensitive data. Security can be improved through enforcing strong and complex passwords, and have the website run regular updates. The web-based application should be considered to be run and used in mobile phones in a form of a mobile web application since most users nowadays access websites through their mobile phones.

\section{REFERENCES}

1. Slaugther, A. (2017). 3 responsibilities every government has towards its citizens. [online] World Economic Forum. Available https://www.weforum.org/agenda/2017/02/governmentresponsibility-to-citizens-anne-marie-slaughter/ [Accessed 10 Mar. 2019].

2. Opengovpartnership.org. (2016). Public Service Delivery | Open Government Partnership. [online] Available at: https://www.opengovpartnership.org/theme/public-servicedelivery [Accessed 14 Apr. 2019].

3. Dudley, E., Lin, D., Mancini, M. and Ng, J. (2018). Implementing a citizen-centric approach to delivering government services. [online] McKinsey \& Company. Available at: https://www.mckinsey.com/industries/publicsector/our-insights/implementing-a-citizen-centric-approachto-delivering-government-services [Accessed 9 Apr. 2019].

4. Dswd.gov.ph. (2015). Organizational Structure | Department of Social Welfare and Development. [online] Available at: https://www.dswd.gov.ph/organizational-structure/ [Accessed 19 Jan. 2019].
5. Dswd.gov.ph. (2015). Residential and Non-Residential Facilities | Department of Social Welfare and Development. [online] Available at: https://www.dswd.gov.ph/programs/residential-and-nonresidential-facilities/ [Accessed 19 Jan. 2019].

6. Marketing, S. (2017). DSWD urges public to report child abuse | Department of Social Welfare and Development. [online] Dswd.gov.ph. Available at: https://www.dswd.gov.ph/dswd-urges-public-to-report-childabuse/ [Accessed 7 Dec. 2018].

7. Bjur, S. (2018). Improving Government Efficiency with Smarter Service Provision. [online] Lp.qmatic.com. Available at: $\quad$ http://lp.qmatic.com/blog/improving-governmentefficiency-with-smarter-service-provision [Accessed 11 May 2019].

8. Ocampo, F. (2017). How will the Philippines' ICT industry change in 2017 and beyond? - Open Access BPO. [online] Open Access BPO. Available at: https://www.openaccessbpo.com/blog/how-will-thephilippines-ict-industry-change-in-2017-and-beyond/ [Accessed 14 Dec. 2018].

9. Verzozain, F. (2012). Promoting records management in government. [online] Slideshare.net. Available at: https://www.slideshare.net/verzosaf/promoting-recordsmanagement-in-government [Accessed 14 Dec. 2018].

10. Lamont Ph.D., J. (2012). Three hot issues in records management. [online] Kmworld.com. Available at: http://www.kmworld.com/Articles/Editorial/Features/Threehot-issues-in-records-management-82032.aspx [Accessed 14 Dec. 2018].

11. Magno, F. and Serafica, R. (n.d.). Information Technology for Good Governance. 1st ed. [ebook] pp.2-3. Available at: http://unpan1.un.org/intradoc/groups/public/documents/apcity /unpan002708.pdf [Accessed 28 Dec. 2018].

12. Hazan, J. (2016). Incident reporting and a culture of safety. Clinical Risk, [online] 22(5-6), pp.83-87. Available at: https://journals.sagepub.com/doi/abs/10.1177/1356262216682 893 [Accessed 10 May 2019]. 